\title{
A Participatory Approach to Improving Retention in HIV Treatment and Care for Newly Diagnosed Patients in a Secondary Health Facility in Sierra Leone
}

\section{Wole Ameyan*, Hannah Kamara, Jaicy Sesay, Mariama Sheriff, Khadija Dumbuya, Mabinty Timbo, Sulaiman Conteh and Etienne Guillard} Solthis, Sierra Leone

\begin{abstract}
The bottom line for any successful HIV program is adherence to therapy and retention in care with the subsequent benefit of achieving undetectable viral levels. Research has shown that poor retention in care for HIV infection has a negative impact on survival and health outcomes. This study aimed to improve retention in care at a secondary health in Freetown, Sierra Leone through a participatory approach that involved health workers and support groups. Our interventions included implementing a participatory needs assessment, reorganising the patient flow, improving communication between health workers and people living with HIVIAIDS (PLHIV), trainings and capacity building and improving the content of support group meetings. The baseline period was from June 2012 to June 2013 while the post intervention period was from June 2013 to June 2014. At baseline, a total of 47 patients were newly diagnosed out of which 19 were male and 28 were female. The median age was 32 . Twenty were single, 18 married, 7 widowed and one divorced with one confirmed dead. In all, 15 were retained in care while 31 were lost to follow up. Our baseline retention was therefore $33 \%$. Post intervention, a total of 54 patients was newly diagnosed out of which 48 were female and six were male. The median age was 29. Twenty were single, 27 married and 7 widowed. Eleven were confirmed dead and 1 asked to be transferred to a nearby facility due to reasons of distance. Thirty nine were retained in care while three were lost to follow up. Our baseline retention was therefore $93 \%$. The results therefore showed that retention in care improved from $33 \%$ to $93 \%$ over a 6 month period. We conclude that while there are generic interventions that could be applied at program level to improve retention in care, interventions need to be context specific and fully participatory to cater to the multi-pronged yet unique peculiarities of every setting.
\end{abstract}

Keywords: Freetown; HIV; Participatory; Retention; Sierra Leone; Treatment

\section{Introduction}

The bottom line for any successful HIV program is adherence to therapy and retention in care with the subsequent benefit of achieving undetectable viral levels. Research has shown that poor retention in care for HIV infection has a negative impact on survival and health outcomes [1,2]. Adherence to ART as a consequence of good retention in care has been shown to have the benefit of not just longer, healthier lives for those on treatment but also the additional effect of limiting transmission by up to $96 \%$ and reducing the risk of maternal to child transfer of HIV to less than 5\% compared to up to $45 \%$ without treatment $[3,4]$.

Retention in care has been a much discussed topic for many HIV programs both in the developed and developing countries along the continuum of care from diagnosis to linkage to care, initiation of HIV therapy, adherence to therapy and achievement of an undetectable viral load. In developed countries, the proportion of all people living with HIV who had an undetectable viral load ranged from $62 \%$ in Australia to a low of just $25 \%$ in the United States. In Denmark, the UK, the Netherlands and France, over 50\% of people living with HIV are reported to have an undetectable viral load (59\%, 58\%, 53\% and 52\%, respectively) [5].

There are pervasive challenges however, to retaining patients in care in resource-limited settings. Available data suggest that only $29 \%$ of people in sub-Saharan African countries were shown to have an undetectable viral load [5]. Lack of proximity to public health facilities for many Africans who reside in rural areas and inadequate transportation have been previously identified as major barriers to retention in care. In addition, health seeking behaviours are often intertwined with competing priorities such as employment seeking and family responsibilities that may take precedence [6]. Importantly, although ART may be free of charge, other out of pockets expenses on health can lead to treatment disruptions [7]. Other factors that have been shown to impede retention in care include stigma and discrimination which interferes with the trust and connectivity that any care seeker needs to remain in care [8-10].

In Sierra Leone, the provision of free ART policy came into effect in 2005 and since then, there has been a significant increase in the uptake of ART services and subsequent scale-up of ART sites. By 2013 , treatment centres had increased to 136 while over 10,000 clients are currently on ART. National program data reveal an obvious high rate of loss to follow up among adults and in other population groups including pregnant women on PMTCT.

For the past 3 years, Solidarité Thérapeutique et Initiatives pour la Santé (Solthis) has been supporting the Ministry of Health through a project to provide care and treatment for people with HIV/AIDS receiving care at Lumley Government Hospital, a densely populated and highly mobile area of Freetown, Sierra Leone. In this article, we

*Corresponding author: Wole Ameyan, Medical Coordinator, Solthis, Sierra Leone, Tel: 07425802519; E-mail: wole.ameyan@solthis.org

Received March 24, 2017; Accepted April 15, 2017; Published April 22, 2017

Citation: Ameyan W, Kamara H, Sesay J, Sheriff M, Dumbuya K, et al. (2017) A Participatory Approach to Improving Retention in HIV Treatment and Care for Newly Diagnosed Patients in a Secondary Health Facility in Sierra Leone. J AIDS Clin Res 8: 686. doi: 10.4172/2155-6113.1000686

Copyright: (c) 2017 Ameyan W, et al. This is an open-access article distributed under the terms of the Creative Commons Attribution License, which permits unrestricted use, distribution, and reproduction in any medium, provided the original author and source are credited. 
describe how our participatory approach to HIV service delivery overcame some of the challenges of poor retention in treatment and care, to achieve a much improved retention rate while building the capacity of health workers for a sustainable achievement of improved quality of care and clinical outcomes.

\section{Methodology}

\section{Methods and interventions}

The project was carried out at Lumley Government Hospital in the western area of Freetown, Sierra Leone. Lumley Government Hospital is a district level hospital in a densely populated area of Freetown. The facility provides a range of HIV services including testing and counselling, treatment and care. This facility currently has about 300 patients who are required to come to the facility every month for their refill.

This project had 4 stages that involved qualitative as well as quantitative needs assessment, analysis and measurements. This study was carried out between June 2012 and July 2014 with the baseline period from June 2012 to June 2013 while the intervention period was from June 2013 to June 2014. The stages include:

- A qualitative participatory needs assessment: Following a stakeholder analysis to identify relevant stakeholders, we conducted 2 participatory assessments with doctors, nurses, HIV counsellors, TB clinic, Maternity, Child Health, and members of the PLHIV support group amongst others at the facility to identify the specific tasks and assignments of the identified stakeholders in the management of HIV patients; assess the current patient flow for HIV diagnosis, treatment and care; identify challenges faced in HIV-patients management; and collectively proffer solutions. The main barriers were then prioritised to arrive at a core list of the most important barriers to retention (Figure 1).

- Assess the current ART retention rates: The baseline retention was measured quantitatively from June 2012 to June 2013. Patient appointment registers also called ART registers at Lumley were used to assess the proportion of patients who started ART during this period and were still on ART

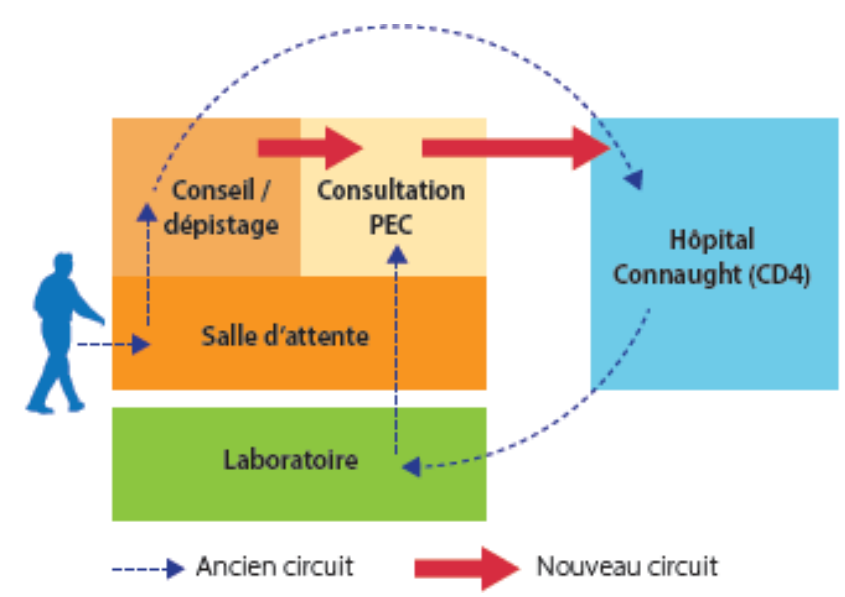

Figure 1: Illustration of patient flow. In the previous flow, patients were out referred to a distant hospital for CD4 soon after testing positive. In the new flow, patients are to go first to the consultation room for further counselling, care, support and management before being our referred.
6 months after. The ART registers are used to register the monthly appointments of patients who come for their monthly dispensing of ART. Patients, who commenced ART from June to December, 2012 were followed for 6 months until June 2013 to determine their 6 month retention. Retention in care was measured as a function of a patients being lost to follow up. We considered a patient 'lost to follow-up' and therefore not retained if such a patient had not presented for care 90 days after the last missed appointment. Dead or patients who had requested to be transferred out of the facility to other facilities due for example to distance were not considered disengaged from care and were therefore removed from the calculations as their outcomes are known and therefore are not 'lost'. For transferred out and dead cases, not only are their outcomes known, they are still having the benefits of ART in other facilities or they cannot be evaluated for consequences of poor retention including transmission to others.

- Initiate and implement interventions to improve ART retention: We define interventions to improve retention as strategies that aim to enhance this important determinant of successful HIV treatment outcomes. Based on the participatory assessments, we identified a list of challenges from which we prioritized a core list of interventions that were arrived at in a participatory manner. These interventions began after the baseline commenced between June 2013 and June 2014.

\section{Changing the patient flow}

Our participatory assessment (Figure 2) showed clearly a flaw in the flow of patients. Our analysis also found that of those patients who were lost to follow up, most of them were lost after the first appointment suggesting a problem in the patient flow. Part of the discussions as to the reason for this was that the flow referred patients out of the facility with little information about their conditions and what to expect. A lack of patient knowledge regarding their treatment and care has been mentioned in many studies as critical barriers to retention in care [1113]. In particular, PLHIV at our participatory assessments mentioned difficulty in understanding their treatment, as a barrier to retention and adherence. Our main intervention under this pilot project was to analyse the patient flow and proffer solutions as to a change in flow in order to maximize the time the patients spend at the facility. Under the previous flow, newly diagnosed patients were to immediately be out referred to distant facilities for CD4 measurements and other laboratory investigations. This out referral happened even before they were linked from testing to care. The new work flow which was arrived

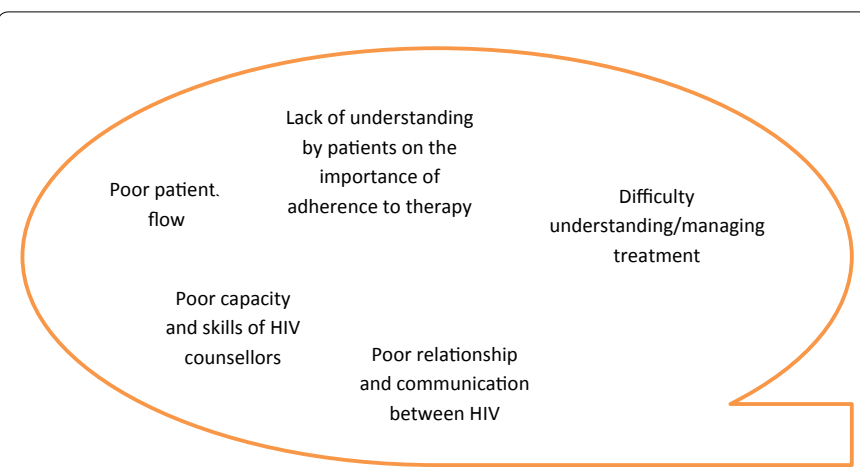

Figure 2: Prioritized barriers to retention at Lumley Hospital as reported in the participatory assessments. 
at in a participatory manner mandates newly diagnosed patients to be referred by HIV testing and counselling (HTC) counsellors to the ART clinic for registration, clinical staging, additional counselling and start of Cotrimoxazole prophylaxis before referral for further investigations outside the facility (Figure 1). The current work was implemented so as to ensure, emphasize and strengthen the link between the HCT and ART clinics.

\section{Improving the line of communication between patient and health worker}

One of the key issues that came out from the PLHIV who attended the participatory assessment was the poor communication between HIV counsellors and newly diagnosed PLHIV especially in the immediate aftermath of a positive result. It was suggested that PLHIV are still very confused when at the consultation room after being diagnosed and are often not in the best frame of mind to ask the relevant natural questions that would normally have come to them. Many of these questions begin to come to them after they would have left the clinic. In the absence of any line of communication, patients are often left in the lurch and without having their most burning questions answered. As a remedy to this, an intervention we provided was a regular cell phone and a contact number card for the facility. This contact card was to be provided for every newly diagnosed patient from the time of the start of interventions (June 2013).

\section{Training and clinical mentoring of HIV counsellors}

Poor service received from healthcare workers have been cited in many studies as a negative predictor of retention [14-18]. The retention of patients in care depends greatly on an able and capable HIV health workforce. When health workers do not have the requisite skills to attend to and manage patients, the quality of care is bound to be poor with potential negative effect on patient retention and outcomes. As part of this pilot project, our interventions were structured to include onsite and classroom training for HIV counsellors at Lumley hospital to build their skills to deliver quality HIV care. On-going clinical mentoring and supportive supervision were also commenced and intensified. Specific topics covered included pre and post-test counselling, adherence counselling and patient education and motivation.

\section{Monthly support groups meetings}

At Lumley Hospital, we strengthened the links between PLHIV support groups and health workers. This was done by facilitating monthly meetings for PLHIV who are members of the support group. At these meetings, adherence to therapy is the main issue discussed. The adherence talks are given by PLHIV who have a good record of adherence and therefore serve as role models. HIV counsellors also formed a part of these meetings and delivered adherence lectures.

- Re-assess post intervention retention - Following the implementation of the interventions over a one year period from June 2013 to June 2014, the retention rates of all patients enrolled from the beginning of the roll-out of the interventions was to be assessed. Patient appointment registers also called ART registers at Lumley were used to assess the proportion of patients still on ART over this period. The ART registers are used to register the monthly appointments of patients who come for their monthly dispensing of ART. Patients, who commenced ART from June 2013 to December, 2013 were followed for 6 months to determine their 6 month retention. Retention in care was measured as a function of a patient being lost to follow up. We considered a patient 'lost to follow-up' and therefore not retained if such a patient had not presented for care at least 90 days after the last appointment. Dead or patients who had requested to be transferred out of the facility to other facilities due for example to distance were not considered disengaged from care and were therefore removed from the calculations as their outcomes are known and therefore are not 'lost'. For transferred out and dead cases, not only are their outcomes known, they are still having the benefits of ART in other facilities or they cannot be evaluated for consequences of poor retention including transmission to others.

The whole process of this project was done in a participatory manner with the involvement of HIV counsellors at the facility as well as PLHIV themselves. The lead of this project is a medical doctor with many years of experience in HIV programming working for Solthis NGO. The data collection and supervision of interventions was done by all involved in the project (lead of the project, HIV counsellors at the facility as well as PLHIV themselves).

Data collected was inputted and analysed using an Excel database. This was done by the HIV counsellors who were trained on this and cross checked and supervised by the lead researcher. The National HIV/ AIDS Control Program was part of the process of this project and gave permission for its implementation and dissemination.

\section{Results}

The result section reports on 2 indicators. First the baseline retention rate and secondly the retention rate, post intervention.

\section{Baseline retention}

To carry out this project, it was necessary to know what the retention was at baseline in order to be able to compare and see if any notable improvements have been observed after the period of interventions. The baseline period was from June 2012 to June 2013. Patients who were lost to follow up i.e. had not presented for care at least 90 days after the last appointment were considered not retained. As done in other similar studies on retention $[1,19]$, dead patients or patients who had requested to be transferred out of the facility to other facilities due for example to distance were not considered disengaged from care and were therefore excluded from the calculations as their outcomes are known and therefore are not 'lost'. In the setting of decentralized HIV services such as in Sierra Leone, a significant number of patients who are deemed lost to follow-up may be retained in care elsewhere in the system [2022] so it was important to distinguish retention in clinic from retention in care in order to avoid biased estimates of the magnitude of patient retention and also potential inaccurate identification of determinants of retention.

Only newly enrolled patients during this period were considered. We measured the 6 month retention rate. Each of those newly enrolled patient was then followed for 6 months to determine if they were retained or not based on the definition. Therefore as the baseline period was from June 2012 to June 2013 and since what we measured was the 6 month retention rate, only newly diagnosed patients from June 2012 to December 2012 were considered and followed for 6 months. In other words, newly diagnosed patients from June 2012 were followed up for 6 months until December 2012; July 2012 until January 2013; August 2012 until February 2013; September 2012 until March 2013; October 2012 until April 2013; November 2012 until May 2013; and patients newly diagnosed in December 2012 were followed until the end of the intervention period in June 2013 (Tables 1 and 2). 
Page 4 of 8

\begin{tabular}{|l|c|}
\hline Type of participants & Number (19 participants) \\
\hline HIV counsellors & 6 \\
\hline PLHIVs & 7 \\
\hline Hospital superintendent & 1 \\
\hline Pharmacist & 1 \\
\hline Laboratory technicians & 2 \\
\hline M\&E Officer & 1 \\
\hline Cleaner & 1 \\
\hline
\end{tabular}

Table 1: List of participants for the participatory assessments.

Comparisons between baseline and post intervention results

\begin{tabular}{|l|c|c|c|}
\hline \multicolumn{4}{|c}{ Comparisons between baseline and post intervention results } \\
\hline & Baseline & Results & P value \\
\hline Total number patients & 46 & 42 & \\
\hline Male & 19 & 4 & \\
\hline Female & 27 & 38 & \\
\hline Median age (Min-Max) (years) & 32 years (16-70) & 29 years (18-62) & \\
\hline Number still in care after 6 months & 15 & 39 & \\
\hline Retention rate at 6 months (\%) & $33 \%$ & $93 \%$ & $<0.001$ \\
\hline
\end{tabular}

Table 2: Comparisons between baseline and post intervention results.

\begin{tabular}{|l|c|c|c|c|c|c|c|c|c|c|c|}
\hline & Total number & Male & Female & \multicolumn{4}{|c|}{ Marital status } & \multicolumn{4}{|c|}{ Results } \\
\cline { 5 - 12 } & & & & M & S & W & D & R & L & Di & TO \\
\hline June & 10 & 2 & 8 & 7 & 3 & 0 & 0 & 5 & 4 & 1 & 0 \\
\hline July & 5 & 3 & 2 & 0 & 5 & 0 & 0 & 1 & 4 & 0 & 0 \\
\hline August & 11 & 7 & 4 & 4 & 5 & 2 & 0 & 2 & 9 & 0 & 0 \\
\hline September & 4 & 3 & 1 & 4 & 0 & 0 & 0 & 2 & 2 & 0 & 0 \\
\hline October & 7 & 4 & 3 & 2 & 2 & 2 & 1 & 1 & 6 & 0 & 0 \\
\hline November & 4 & 0 & 4 & 0 & 2 & 2 & 0 & 0 & 4 & 0 & 0 \\
\hline December & 6 & 0 & 6 & 2 & 3 & 1 & 0 & 4 & 2 & 0 & 0 \\
\hline Total & 47 & 19 & 28 & 19 & 20 & 7 & 1 & 15 & 31 & 1 & 0 \\
\hline
\end{tabular}

M: Married; S: Single; W: Widowed; D: Divorced; R: Retained; L: Lost to follow up Di: Died; TO: Transferred Out

Table 3: Baseline retention disaggregated by month

Tables 3 and 4 show the baseline retention disaggregated by month and the patient by patient analysis respectively. In all, a total of 47 patients were newly diagnosed from June 2012 to December 2012 out of which 19 were male and 28 were female. The median age was 32.20 were single, 18 were married, 7 were widowed and 1 was divorced.

Out of a total number of 47 patients, 1 was confirmed dead. 15 were retained in care while 31 had been lost to follow up. Our baseline retention was therefore $33 \%\left[15 /\{47-1\}^{\star} 100\right]$. The one confirmed dead was a 29 year old married female. Out of those that were retained, the median age was 29 with 9 females and 6 males. 7 were married, 6 were single, 1 was widowed and 1 was divorced. Of those that were lost to follow up, the median age was 32 with 18 females and 13 males. 11 were married, 14 were single and 6 were widowed.

\section{Post-intervention retention}

Our interventions started in June 2013 and lasted for a period of 12 months until June 2014. We used the same parameters as used for baseline retention to calculate our post intervention retention rate. The results have been outstanding.

As in the baseline, patients who had disengaged from care i.e. had not presented for care at least 90 days after the last appointment were considered not retained. We did not consider dead or patients who had requested to be transferred out of the facility to other facilities due for example to distance and were therefore removed from the calculations. We measured the 6 month retention rate for newly enrolled patients

\begin{tabular}{|c|c|c|c|c|}
\hline & \multicolumn{4}{|c|}{ Baseline } \\
\hline & Age & Sex & Marital status & Retention \\
\hline \multirow{10}{*}{ JUNE } & 27 & $\mathrm{~F}$ & $S$ & L \\
\hline & 30 & $\mathrm{~F}$ & $M$ & $\mathrm{R}$ \\
\hline & 22 & $M$ & $S$ & $R$ \\
\hline & 50 & $\mathrm{~F}$ & $M$ & L \\
\hline & 38 & $M$ & $M$ & $\mathrm{R}$ \\
\hline & 49 & $\mathrm{~F}$ & $M$ & L \\
\hline & 24 & $\mathrm{~F}$ & $S$ & $\mathrm{R}$ \\
\hline & 29 & $\mathrm{~F}$ & $M$ & $\mathrm{Di}$ \\
\hline & 27 & $\mathrm{~F}$ & M & $\mathrm{L}$ \\
\hline & 32 & $\mathrm{~F}$ & M & $\mathrm{R}$ \\
\hline \multirow{5}{*}{ JULY } & 33 & M & $s$ & L \\
\hline & 28 & $\mathrm{~F}$ & $\mathrm{~s}$ & $\mathrm{~L}$ \\
\hline & 34 & $M$ & $S$ & $\mathrm{R}$ \\
\hline & 39 & M & $s$ & L \\
\hline & 48 & $\mathrm{~F}$ & $\mathrm{~s}$ & $\mathrm{~L}$ \\
\hline \multirow{11}{*}{ AUGUST } & 40 & $M$ & $\mathrm{~s}$ & L \\
\hline & 31 & $\mathrm{~F}$ & M & $\mathrm{L}$ \\
\hline & 28 & $\mathrm{~F}$ & 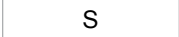 & $\mathrm{L}$ \\
\hline & 25 & $\mathrm{~F}$ & M & $\mathrm{L}$ \\
\hline & 28 & $\mathrm{~F}$ & $M$ & $R$ \\
\hline & 28 & M & $\mathrm{s}$ & $\mathrm{L}$ \\
\hline & 36 & $M$ & M & $\mathrm{L}$ \\
\hline & 45 & $M$ & W & $\mathrm{L}$ \\
\hline & 45 & M & W & $\mathrm{L}$ \\
\hline & 32 & M & $s$ & $\mathrm{~L}$ \\
\hline & 32 & $M$ & $s$ & $\mathrm{R}$ \\
\hline \multirow{4}{*}{ SEPTEMBER } & 37 & M & M & $\mathrm{R}$ \\
\hline & 42 & M & M & $\mathrm{R}$ \\
\hline & 46 & $M$ & $M$ & L \\
\hline & 26 & $\mathrm{~F}$ & M & $\mathrm{L}$ \\
\hline \multirow{7}{*}{ OCTOBER } & 49 & $\mathrm{~F}$ & W & $L$ \\
\hline & 35 & M & W & $\mathrm{L}$ \\
\hline & 61 & $\mathrm{M}$ & $S$ & L \\
\hline & 44 & $M$ & M & $\mathrm{L}$ \\
\hline & 28 & $\mathrm{~F}$ & $M$ & L \\
\hline & 30 & $\mathrm{~F}$ & D & $\mathrm{R}$ \\
\hline & 26 & M & $s$ & $\mathrm{~L}$ \\
\hline \multirow{4}{*}{ NOVEMBER } & 18 & $\mathrm{~F}$ & $S$ & L \\
\hline & 70 & $\mathrm{~F}$ & W & $L$ \\
\hline & 28 & $\mathrm{~F}$ & $s$ & $\mathrm{~L}$ \\
\hline & 42 & $\mathrm{~F}$ & W & $L$ \\
\hline \multirow{6}{*}{ DECEMBER } & 42 & $\mathrm{~F}$ & W & $\mathrm{R}$ \\
\hline & 36 & $\mathrm{~F}$ & $S$ & $\mathrm{R}$ \\
\hline & 28 & $\mathrm{~F}$ & $\mathrm{~s}$ & $\mathrm{R}$ \\
\hline & 30 & $\mathrm{~F}$ & $M$ & $R$ \\
\hline & 16 & $\mathrm{~F}$ & $\mathrm{~s}$ & $\mathrm{~L}$ \\
\hline & 47 & $\mathrm{~F}$ & M & $\mathrm{L}$ \\
\hline
\end{tabular}

M: Married; S: Single; W: Widowed; D: Divorced; R: Retained; L: Lost to follow up Di: Died; TO: Transferred Out

Table 4: Patient by patient analysis of baseline retention.

during the intervention period. Each of those newly enrolled patient was then followed for 6 months to determine if they were retained or not based on the definition. Therefore as the intervention period was from June 2013 to June 2014 and since what we measured was the 6 
Page 5 of 8

month retention rate, only newly diagnosed patients from June 2013 to December 2014 were considered and followed for 6 months. Therefore, newly diagnosed patients from June 2013 were followed up for 6 months until December 2013; July 2013 until January 2014; August 2013 until February 2014; September 2013 until March 2014; October 2013 until April 2014; November 2013 until May 2014; and patients newly diagnosed in December 2013 were followed until the end of the intervention period in June 2014.

Tables 5 and 6 show the post intervention retention disaggregated by month and the patient by patient analysis respectively. In all, a total of 54 patients were newly diagnosed from June 2013 to December 2013 out of which 48 were female and 6 were male. The median age was 29 . 20 were single, 27 were married and 7 were widowed.

Out of a total number of 54 patients, 11 were confirmed dead and 1 asked to be transferred to a nearby facility due to reasons of distance. 39 were retained in care while 3 were lost to follow up. Our post intervention retention was therefore $93 \%$ [39/ $\left.\{54-12\}^{*} 100\right]$. Out of those that died, the median age was 29 with 10 females and 1 male. 7 were single, 2 were married and 2 were widowed. The one person who requested to be transferred to another facility was a 43 year old single male. Of those that were retained, the median age was 29 with 36 females and 3 males. 24 were married, 10 were single and 5 were widowed. Of the 3 lost to follow up, they were all females with one 29 years old and married, another 22 years, married and the other 18 years old and single.

\section{Discussion}

In discussing retention in care and strategies to improving retention, two things need to be brought to mind: First, in settings where the standards of care differs from facility to facility, the barriers to retention in care and therefore strategies to improving same will most likely vary from setting to setting and from facility to facility. Second, the retention of patients in care does not begin and end with patients' practices but also on other critical factors including the role of the health worker, the conduciveness of the facility amongst others. Therefore retention in care needs to be seen as a collaborative endeavour and should require a multidisciplinary and participatory approach. The participatory nature of this study ensured that from the beginning stakeholders including PLHIV, HIV counsellors, hospital pharmacists, cleaners and superintendent were engaged to discuss in an open atmosphere devoid of any restrictions (Table 1 for list of participants). The involvement of PLHIV through their support groups follows the principle of greater involvement of PLHIV that aims to realize the rights and responsibilities of people living with HIV, including their right to self-determination and participation in decision-making processes that affect their lives

\begin{tabular}{|l|c|c|c|c|c|c|c|c|c|c|c|}
\hline & \multirow{2}{*}{$\begin{array}{c}\text { Total } \\
\text { number of } \\
\text { patients }\end{array}$} & \multirow{2}{*}{ Male } & \multirow{2}{*}{ Female } & \multicolumn{4}{|c|}{ Marital status } & \multicolumn{4}{|c|}{ Result } \\
\cline { 5 - 13 } & & M & S & W & D & R & L & Di & TO \\
\hline June & 6 & 0 & 6 & 4 & 1 & 1 & 0 & 3 & 0 & 3 & 0 \\
\hline July & 8 & 0 & 8 & 4 & 1 & 3 & 0 & 6 & 0 & 2 & 0 \\
\hline August & 8 & 0 & 8 & 5 & 2 & 1 & 0 & 5 & 0 & 3 & 0 \\
\hline September & 11 & 2 & 9 & 7 & 3 & 1 & 0 & 8 & 1 & 1 & 1 \\
\hline October & 7 & 3 & 4 & 2 & 4 & 1 & 0 & 5 & 2 & 0 & 0 \\
\hline November & 5 & 0 & 5 & 1 & 4 & 0 & 0 & 5 & 0 & 0 & 0 \\
\hline December & 9 & 0 & 9 & 4 & 5 & 0 & 0 & 7 & 2 & 0 & 0 \\
\hline Total & 54 & 5 & 49 & 27 & 20 & 7 & 0 & 39 & 3 & 11 & 1 \\
\hline
\end{tabular}

M: Married; S: Single; W: Widowed; D: Divorced; R: Retained; L: Lost to follow up; Di: Died; TO: Transferred Out

Table 5: Post intervention retention disaggregated by month.

\begin{tabular}{|c|c|c|c|c|}
\hline & \multicolumn{4}{|c|}{ Post intervention } \\
\hline & Age & Sex & Marital status & Retention \\
\hline \multirow{6}{*}{ JUNE } & 18 & $\mathrm{~F}$ & $\mathrm{~s}$ & $\mathrm{Di}$ \\
\hline & 54 & $\mathrm{~F}$ & M & $\mathrm{R}$ \\
\hline & 32 & $\mathrm{~F}$ & W & $\mathrm{Di}$ \\
\hline & 60 & $\mathrm{~F}$ & M & $\mathrm{Di}$ \\
\hline & 41 & $\mathrm{~F}$ & $M$ & $\mathrm{R}$ \\
\hline & 30 & $\mathrm{~F}$ & M & $\mathrm{R}$ \\
\hline \multirow{8}{*}{ JULY } & 62 & $\mathrm{~F}$ & W & $\mathrm{R}$ \\
\hline & 29 & $\mathrm{~F}$ & $M$ & $\mathrm{R}$ \\
\hline & 45 & $\mathrm{~F}$ & M & $\mathrm{Di}$ \\
\hline & 30 & $\mathrm{~F}$ & $M$ & $\mathrm{R}$ \\
\hline & 25 & $\mathrm{~F}$ & S & $\mathrm{Di}$ \\
\hline & 36 & $\mathrm{~F}$ & W & $\mathrm{R}$ \\
\hline & 48 & $\mathrm{~F}$ & W & $\mathrm{R}$ \\
\hline & 51 & $\mathrm{~F}$ & M & $\mathrm{R}$ \\
\hline \multirow{8}{*}{ AUGUST } & 52 & $\mathrm{~F}$ & W & $\mathrm{Di}$ \\
\hline & 22 & $\mathrm{~F}$ & $s$ & $\mathrm{Di}$ \\
\hline & 23 & $\mathrm{~F}$ & $s$ & $\mathrm{Di}$ \\
\hline & 33 & $\mathrm{~F}$ & M & $\mathrm{R}$ \\
\hline & 35 & $\mathrm{~F}$ & M & $\mathrm{R}$ \\
\hline & 29 & $\mathrm{~F}$ & M & $\mathrm{R}$ \\
\hline & 29 & $\mathrm{~F}$ & M & $\mathrm{R}$ \\
\hline & 24 & $\mathrm{~F}$ & $M$ & $\mathrm{R}$ \\
\hline \multirow{11}{*}{ SEPTEMBER } & 40 & M & M & $\mathrm{R}$ \\
\hline & 32 & M & M & $\mathrm{R}$ \\
\hline & 27 & $\mathrm{~F}$ & M & $\mathrm{R}$ \\
\hline & 51 & $\mathrm{~F}$ & W & $\mathrm{R}$ \\
\hline & 29 & $\mathrm{~F}$ & M & $\mathrm{L}$ \\
\hline & 26 & $\mathrm{~F}$ & M & $\mathrm{R}$ \\
\hline & 28 & $\mathrm{~F}$ & S & $\mathrm{Di}$ \\
\hline & 38 & $\mathrm{~F}$ & M & $\mathrm{R}$ \\
\hline & 24 & $\mathrm{~F}$ & $s$ & $\mathrm{R}$ \\
\hline & 27 & $\mathrm{~F}$ & M & $\mathrm{R}$ \\
\hline & 43 & $\mathrm{M}$ & $\mathrm{s}$ & TO \\
\hline \multirow{7}{*}{ OCTOBER } & 27 & M & $s$ & $\mathrm{R}$ \\
\hline & 23 & $\mathrm{~F}$ & M & $\mathrm{R}$ \\
\hline & 19 & $\mathrm{~F}$ & $S$ & $\mathrm{Di}$ \\
\hline & 30 & M & $S$ & $\mathrm{R}$ \\
\hline & 32 & $\mathrm{~F}$ & M & $\mathrm{R}$ \\
\hline & 28 & M & $\mathrm{s}$ & $\mathrm{Di}$ \\
\hline & 31 & $\mathrm{~F}$ & W & $\mathrm{R}$ \\
\hline \multirow{5}{*}{ NOVEMBER } & 40 & $\mathrm{~F}$ & M & $\mathrm{R}$ \\
\hline & 32 & $\mathrm{~F}$ & $\mathrm{~s}$ & $\mathrm{R}$ \\
\hline & 31 & $\mathrm{~F}$ & s & $\mathrm{R}$ \\
\hline & 20 & $\mathrm{~F}$ & $\mathrm{~s}$ & $\mathrm{R}$ \\
\hline & 20 & $\mathrm{~F}$ & $\mathrm{~s}$ & $\mathrm{R}$ \\
\hline \multirow{9}{*}{ DECEMBER } & 18 & $\mathrm{~F}$ & $\mathrm{~s}$ & $\mathrm{~L}$ \\
\hline & 43 & $F$ & $M$ & $\mathrm{R}$ \\
\hline & 27 & $\mathrm{~F}$ & $S$ & $\mathrm{R}$ \\
\hline & 29 & $\mathrm{~F}$ & $S$ & $R$ \\
\hline & 20 & $\mathrm{~F}$ & $S$ & $\mathrm{R}$ \\
\hline & 24 & $\mathrm{~F}$ & $M$ & $\mathrm{R}$ \\
\hline & 18 & $F$ & $S$ & $\mathrm{R}$ \\
\hline & 22 & $F$ & $\mathrm{M}$ & L \\
\hline & 28 & $\mathrm{~F}$ & $M$ & $\mathrm{R}$ \\
\hline
\end{tabular}

M: Married; S: Single; W: Widowed; D: Divorced; R: Retained; L: Lost to follow up; Di: Died; TO: Transferred Out

Table 6: Patient by patient analysis of post intervention retention. 
(UNAIDS 1999). Our participatory approach parallels those of Peggy B. Smith whose participatory learning and action approach found this could be an effective way to learn about problems and how to improve engagement of HIV-positive persons in care [23].

One of the most significant findings of the participatory assessments at the facility was the revelation about the flow of patients and how it had the tendency to impact linkage to care and retention. We drew on a flip chart, the flow of patients which revealed major flaws in the way patients were guided through care at the facility. In the previous flow which one of the PLHIV participants described as 'confusing for $u s$ ', patients were referred to a distant facility miles and miles away for CD4 testing as soon as they were tested positive. Usually when they go for this test, they are subject to delays and a potentially unfriendly environment. At the time of this out referral for CD4, many patients had yet to be given any form of detailed counselling and are still at sea as to what their new diagnosis means and how it will impact on their lives and that of their families and loved ones. It is no wonder that many simply just refuse to come back to care. The new patient flow changes this significantly. Now newly diagnosed patients are to be counselled appropriately, sent to the treatment room where further counselling is done, bio-data registration is done, a patient file opened and they are clinically staged, Cotrimoxazole started, before they are then out referred for CD4 testing. Difficulty understanding their treatment as a barrier to retention and adherence has been mentioned in various other studies [24-29]. The need for a patient flow that puts the needs of patients at the core of care and management needs to be further looked into in interventions aimed at improving the quality of HIV care, treatment and support.

Lack of understanding of why it is important to enrol in care as a barrier to retention has been identified in other papers [30] while adherence counselling as a strategy to improving retention in care in different settings $[31,32]$ is mentioned in other contexts. A particular finding of our participatory assessments was the lack of capacity of HIV counsellors to assess adherence, as well as lack of standardized ways of assessing retention, poor options for dealing with issues of poor adherence and retention. One of the interventions of this project was therefore training of HIV counsellors on patient management and adherence assessment and counselling.

PLHIV networks and support groups are a bedrock of many a PLHIV for succour, peer assurance and comfort. PLHIV form support groups to give and receive emotional, social and spiritual support. They also form support groups to develop and sustain positive strategies for living with the virus and to strengthen their knowledge about HIV and AIDS [33]. At baseline, the PLHIV support group at this facility was poorly structured and deeply fragmented. The participatory assessment revealed many issues including irregular meetings, poor capacity, leadership squabbles, poor meeting content. We galvanised the stakeholders including PLHIV themselves to come together and strengthen this group for the betterment of those receiving care at this facility. The monthly support group meeting were restructured with key messages adapted for adherence counselling while HIV counsellors and hospital administrative officials who had hitherto not been a part of the HIV clinic were now in regular attendance. With better messages and participation of the hospital administration, the membership and attendance of the support group meetings swelled to great effect.

The participatory assessment highlighted the need to improve communication with newly diagnosed patents especially in the period following the first few visits. It was therefore important to develop the intrapersonal relationship between patients and HIV counsellors

\begin{tabular}{|l|}
\hline \multicolumn{1}{|c|}{ Fears and concerns raised by newly diagnosed PLHIVs } \\
\hline Side effects of medication \\
\hline Influence of friends and relatives asking them to stop taking medication \\
\hline Permission to postpone appointment date \\
\hline Permission to discontinue treatment \\
\hline Concomitant use of traditional medicine \\
\hline Consequences of treatment interruption \\
\hline Duration of ART treatment \\
\hline Effectiveness of treatment \\
\hline Prospect of death \\
\hline Disclosure \\
\hline What is the cause of HIV, can it be cured? \\
\hline Stigma and discrimination \\
\hline Anxiety over confidentiality \\
\hline
\end{tabular}

Table 7: Most common questions rose by patients who called the facility phone.

especially after the first visit when patients are still very confused and are often not in the best frame of mind to ask the relevant questions that would normally have come to them. Many of these questions begin to come to them after they have left the clinic. In the absence of any line of communication, patients are often left in the lurch and without having their most burning questions answered. To this end, we procured a simple mobile phone and printed contact cards to be provided to all patients. From the phone records, we found that many patients called the number to discuss various issues regarding to their care (how long will I take this for? Will I have to disclose? Can I come before my appointment date?) Table 7 shows the most common questions raised by patients who called as revealed by the HIV counsellors.

This main goal of writing this paper was to share experiences of what has worked in this setting. We did not intend and have not looked at different variables as predictors of retention. However we must note that more females than males were lost to follow up in this study. This differs from other studies in a number of settings that find male sex a predictor of poor retention [34] (Geng retention) including in a multisite study from West Africa [35], South Africa [36], Western Kenya [37] and Malawi [38].

Our method for measuring retention was through the use of appointment registers. As stated in other studies [19], there is no clear gold standard to measure retention in HIV care, and each method studied may have context specific advantages and disadvantages. However, there is the need for standards to be set in this regard for comparison and quality purposes.

\section{Limitations}

From a baseline of $33 \%$, we succeeded in improving retention to an outstanding 93\%. It is hard to find a causal link between the improved retention and our interventions; this was not a controlled study so we acknowledge that there may have been other factors which may have contributed to this remarkably improved retention outside of our interventions. The results for this study relied on data from paper based ART registers with potential space for errors. While we ensured close supervision of the use of ART registers to make such errors limited, it appropriate to mention this. Our retention measures considered only those for whom outcomes are unknown as lost to follow up and therefore not retained in care. Known outcomes including the dead and transferred out were not considered 'lost' for reasons of terminology. Therefore such known outcomes were removed from the denominator Had we included known outcomes such as those that had died as lost to follow up, our retention rate would still have been remarkable at 
Citation: Ameyan W, Kamara H, Sesay J, Sheriff M, Dumbuya K, et al. (2017) A Participatory Approach to Improving Retention in HIV Treatment and Care for Newly Diagnosed Patients in a Secondary Health Facility in Sierra Leone. J AIDS Clin Res 8: 686. doi: 10.4172/2155-6113.1000686

$72 \%$ but much less than our current estimates of $93 \%$. Our assessment of retention was for a relatively short period of time ( 6 months). This project had a small sample size and was carried out in one facility in the western urban district of Sierra Leone. The findings of this study may therefore not be applicable to other areas with different contexts, environments, features and influences.

\section{Conclusion}

Improving the outcomes of HIV/AIDS treatment programs requires successful linkages from the initial diagnosis through the continuum of care. Better and more efficient systems that allow patients to be tracked between service delivery points are needed to properly deal with issues regarding loss to follow up and care.

This study demonstrates that retention in care is a unique dilemma and hydra headed phenomenon that demands a multifaceted approach. Indeed, the task of improving retention in care is one that must be seen as a product of collaborative and expansive efforts involving all stakeholders in the HIV and health system.

The flow of patients along the continuum of care is a very important issue that needs to be reviewed in order to identify potential gaps and barriers to retention. In this facility, we found major gaps in the flow of patients which were changed to emphasize putting the needs of patients at the centre of HIV service delivery. While CD4 and other laboratory investigations may be valuable investigations in the assessment and monitoring of PLHIV, it should not replace the need for therapeutic education and for patients to be more properly assessed, registered in care and counselled.

Advocacy for the greater involvement of stakeholders needs to be sustained. Our participatory approach to dealing with issues pertaining to retention is novel, unique and should be promoted as a standard for designing programs on retention. The planning, implementation, monitoring and evaluation of this project have been done in a participatory and collaborative way. The inclusion of stakeholders including PLHIV themselves illustrates our thinking that retention in care has to be viewed and managed as a multidisciplinary effort that identifies and assigns responsibilities on improving retention in care.

Retention in HIV care still remains a huge problem affecting the progress and successful implementation of HIV programs. While there may be generic interventions that could be applied at program level to improve retention in care, interventions need to be context specific and fully participatory to cater to the multi-pronged yet unique peculiarities of every setting. Moving forward, the lessons from this project could inform future strategies and interventions at hospitals, clinics and in other settings with similar contexts, backgrounds and environments.

\section{Acknowledgement}

This retention project was carried out as part of the country program activities of Solidarité Thérapeutique et Initiatives pour la Santé (Solthis) in Sierra Leone. All the authors declare no conflicts of interest. We would like to thank the National HIVIAIDS Control Program in Sierra Leone, members of the PLHIV support group at Lumley Government Hospital and all the staff and PLHIV at Lumley Government Hospital.

\section{References}

1. Giordano TP, Gifford AL, White AC Jr, Suarez-Almazor ME, Rabeneck L, et al. (2007) Retention in care: A challenge to survival with HIV infection. Clin Infect Dis 44: 1493-1499.

2. Horstmann E, Brown J, Islam F, Buck J, Agins BD (2010) Retaining HIVinfected patients in care: Where are we? Where do we go from here? Clin Infect Dis 50: 752-761.
3. Cohen MS, McCauley M, Gamble TR (2012) HIV treatment as prevention and HPTN 052. Curr Opin HIV AIDS 7: 99-105.

4. WHO (2014) HIVIAIDS: Prevention of mother-to-child HIV transmission.

5. Raymond A, Hill A, Pozniak A (2014) Large disparities in HIV treatment cascades between eight European and high-income countries-analysis of break points. J Int AIDS Soc 17: 19507.

6. Geng EH, Nash D, Kambugu A, Zhang Y, Braitstein P, et al. (2010) Retention in care among HIV-infected patients in resource-limited settings: Emerging insights and new directions. Curr HIVIAIDS Rep 7: 234-244.

7. Deribe K, Hailekiros F, Biadgilign S, Amberbir A, Beyene BK (2008) Defaulters from antiretroviral treatment in Jimma University specialized hospital Southwest Ethiopia. Trop Med Int Health 13: 328-333.

8. Naar-King S, Bradford J, Coleman S, Green-Jones M, Cabral H, et al. (2007) Retention in care of persons newly diagnosed with HIV: Outcomes of the Outreach Initiative. AIDS Patient Care STDS 21: S40-S48.

9. Rintamaki LS, Davis TC, Skripkauskas S, Bennett CL, Wolf MS (2006) Socia stigma concerns and HIV medication adherence. AIDS Patient Care STDS 20 359-368.

10. Kempf MC, McLeod J, Boehme AK, Walcott MW, Wright L, et al. (2010) A qualitative study of the barriers and facilitators to retention-in-care among HIV-positive women in the rural south-eastern United States: Implications for targeted interventions. AIDS Patient Care STDs 24: 515-520.

11. Rintamaki LS, Davis TC, Skripkauskas S, Bennett CL, Wolf MS (2006) Socia stigma concerns and HIV medication adherence. AIDS Patient Care STDS 20 359-368.

12. Roberts KJ (2000) Barriers to and facilitators of HIV-positive patient's adherence to antiretroviral treatment regimens. AIDS Patient Care STDs 14: 155-168.

13. Cheever LW (2007) Engaging HIV-infected patients in care: Their lives depend on it. Clin Infect Dis 44: 1500-1502.

14. Luseno W, Wechsberg W, Middlesteadt-Ellerson R, Gumula W (2008) Linkages and barriers to care for high-risk South African women testing positive for HIV. AIDS, Mexico City, Mexico.

15. McGuire M, Munyenyembe T, Szumilin E, Heinzelmann A, Le Paih M, et al (2010) Vital status of pre-ART and ART patients defaulting from care in rura Malawi. Trop Med Int Health 15: 55-62.

16. Duff P, Kipp W, Wild TC, Rubaale T, Okech-Ojony J (2010) Barriers to accessing highly active antiretroviral therapy by HIV-positive women attending an antenatal clinic in a regional hospital in western Uganda. J Int AIDS Soc 13: $1-9$.

17. Mshana GH, Wamoyi J, Busza J, Zaba B, Changalucha J, et al. (2006) Barriers to accessing antiretroviral therapy in Kisesa, Tanzania: A qualitative study of early rural referrals to the national program. AIDS Patient Care STDS 20: 649657.

18. Fox MP, Mazimba A, Seidenberg P, Crooks D, Sikateyo B, et al. (2010) Barriers to initiation of antiretroviral treatment in rural and urban areas of Zambia: $A$ cross-sectional study of cost, stigma, and perceptions about ART. J Int AIDS Soc 13: 8.

19. Mugavero MJ, Westfall AO, Zinski A, Davila J, Drainoni ML, et al. (2012) Measuring retention in HIV care: The elusive gold standard. J Acquir Immune Defic Syndr 61: 574-580.

20. Amuron B, Namara G, Birungi J, Nabiryo C, Levin J, et al. (2009) Mortality and loss-to-follow-up during the pre-treatment period in an antiretroviral therapy programme under normal health service conditions in Uganda. BMC Public Health 9: 290 .

21. Maskew M, MacPhail P, Menezes C, Rubel D (2007) Lost to follow up: Contributing factors and challenges in South African patients on antiretroviral therapy. S Afr Med J 97: 853-857.

22. Dalal RP, Macphail C, Mqhayi M (2008) Characteristics and outcomes of adult patients lost to follow-up at an antiretroviral treatment clinic in Johannesburg South Africa. J Acquir Immune Defic Syndr 47: 101-107.

23. Buzi RS, Smith PB, Siceluff A (2009) A participatory learning and action (PLA) approach to enhancing linkage to HIV care among youth. J Adolesc Health 21:78-86.

24. Murray LK, Semrau K, McCurley E, Thea DM, Scott N, et al. (2009) Barriers to 
Citation: Ameyan W, Kamara H, Sesay J, Sheriff M, Dumbuya K, et al. (2017) A Participatory Approach to Improving Retention in HIV Treatment and Care for Newly Diagnosed Patients in a Secondary Health Facility in Sierra Leone. J AIDS Clin Res 8: 686. doi: 10.4172/2155-6113.1000686

acceptance and adherence of antiretroviral therapy in urban Zambian women: A qualitative study. AIDS Care 21: 78-86.

25. Fassinou P, Elenga N, Rouet F, Laguide R, Kouakoussui KA, et al. (2004) Highly active antiretroviral therapies among HIV-1-infected children in Abidjan, Côte d'Ivoire. AIDS 18: 1905-1913.

26. Cupsa A, Gheonea C, Bulucea D, Dinescu S (2000) Factors with a negative influence on compliance to antiretroviral therapies. Ann N Y Acad Sci 918: 351 354.

27. Brigido LF, Rodrigues R, Casseb J, Oliveira D, Rossetti M, et al. (2001) Impact of adherence to antiretroviral therapy in HIV-1-infected patients at a university public service in Brazil. AIDS Patient Care STDS 15: 587-593.

28. Hofer CB, Schechter M, Harrison LH (2004) Effectiveness of antiretroviral therapy among patients who attend public HIV clinics in Rio de Janeiro, Brazil. J Acquir Immune Defic Syndr 36: 967-971.

29. Sanjobo N, Frich JC, Fretheim A (2008) Barriers and facilitators to patients' adherence to antiretroviral treatment in Zambia: A qualitative study. SAHARA J 5: 136-143.

30. Govindasamy D, Ford N, Kranzer K (2012) Risk factors, barriers and facilitators for linkage to antiretroviral therapy care: A systematic review. AIDS 26: 2059-2067.

31. Chesney MA (2006) The elusive gold standard: Future perspectives for HIV adherence assessment and intervention. J AIDS 43: S149-S155.
32. Sherer R, Stieglitz K, Narra J, Jasek J, Green L, et al. (2002) HIV multidisciplinary teams work: Support services improve access to and retention in HIV primary care. AIDS Care 14: S31-S44.

33. Guidelines for establishing and operating successful support groups for people living with HIV. CRS.

34. Geng EH, Nash D, Kambugu A, Zhang Y, Braitstein P, et al. (2010) Retention in care among HIV-infected patients in resource-limited settings: Emerging insights and new directions. Curr HIVIAIDS Rep 7: 234-244.

35. Ekouevi DK, Balestre E, Ba-Gomis FO, Eholie SP, Maiga M, et al. (2010) Low retention of HIV-infected patients on antiretroviral therapy in 11 clinical centres in West Africa. Trop Med Int Health 15: 34-42.

36. Maskew M, MacPhail P, Menezes C, Rubel D (2007) Lost to follow up: contributing factors and challenges in South African patients on antiretroviral therapy. S Afr Med J 97: 853-857.

37. Ochieng-Ooko V, Ochieng D, Sidle JE, Holdsworth M, Wools-Kaloustian K, e al. (2010) Influence of gender on loss to follow-up in a large HIV treatment programme in western Kenya. Bull World Health Organ 88: 681-688.

38. Makombe SD, Jahn A, Tweya H, Chuka S, Yu JK, et al. (2007) A national survey of teachers on antiretroviral therapy in Malawi: Access, retention in therapy and survival. PLoS ONE 2: e620. 